\title{
Implementasi Simple Additive Weighting untuk Rekomendasi Pemilihan Jurusan pada Sekolah Menengah Kejuruan
}

\author{
Robi Aziz Zuama ${ }^{1}$, Irwan Agus Sobari \\ ${ }^{1}$ Sistem Informasi; Fakultas Teknologi Informasi; Universitas Bina Saran Informatika \\ e-mail: ${ }^{1}$ robi.rbz@bsi.ac.id \\ ${ }^{2}$ Teknik Informatika; STMIK Nusa Mandiri \\ e-mail: ${ }^{2}$ irwan.igb@ nusamandiri.ac.id

\begin{tabular}{ccc}
\hline Diterima & Direvisi & Disetujui \\
$10-12-2019$ & $13-12-2019$ & $17-12-2019$ \\
\hline
\end{tabular}

\begin{abstract}
Abstrak - Pemilihan jurusan yang tepat bagi siswa baru akan berdampak besar pada kemampuan siswa itu sendiri. Pemilihan jurusan menjadi sangat penting, karena siswa dapat menentukan jurusan yang akan membawa ke passion-nya di masa depan, dengan jurusan yang tepat, siswa akan lebih tertarik dalam proses belajarnya. Dalam memilih jurusan, biasanya siswa bertanya kepada yang bukan ahli pada bidang tersebut seperti orang tua, teman sebaya, orang-orang terdekat atau bahkan menentukan jurusan dengan berlandaskan kepopuleran suatu jurusan tersebut, padahal jurusan tersebut, belum tentu menjadi passion siswa tersebut. Metode simple adaptive weighting (SAW) dapat membantu siswa dalam menentukan jurusan yang dipilih, SAW dapat membuat rekomendasi jurusan yang tepat, berdasarkan kriteria-kriteria terukur dari kemampuan siswa itu sendiri. penelitian ini mengusulkan metode Simple Additive Weighting karena perhitungan yang simple dan berlandaskan bobot kemampuan siswa itu sendiri. Hasilnya siswa mendapatkan rekomendasi-rekomendasi dari hasil perhitungan bobot dari setiap alternatif jurusan sesuai dengan kemampuan siswa itu sendiri, dengan metode ini siswa tidak lagi salah mengambil jurusan.
\end{abstract}

Kata Kunci: Simple Adaptive Weighting, Rekomendasi, Jurusan, Kriteria.

\section{PENDAHULUAN}

Sekitar $63 \%$ orang indonesia bekerja tidak sesuai dengan jurusan yang diambilnya, menteri ketenaga kerjaan Hanif Dhakiri mengatakan, hanya sekitar $37 \%$ angkatan kerja yang bekerja sesuai dengan jurusan yang ditekuni (Yeni Kustiyahningsih \& Syafa'ah, 2014). Pemilihan jurusan menjadi sangat penting, karena siswa dituntut untuk memilih jurusan yang sesuai dengan minat, bakat dan jurusan yang diambil harus sesuai dengan kemampuan siswa itu sendiri (Yeni Kustiyahningsih \& Syafa'ah, 2014).

Berbeda dengan SMA atau MA siswa lulusan menengah pertama akan lebih mudah memilih penjurusan, karena hanya sedikit pilihan yang akan diambil, sedangkan untuk siswa yang akan melanjutkan ke tingkat SMK akan sedikit lebih sulit menentukan jurusan yang akan dipilih karena banyaknya jurusan yang ditawarkan (Sucipto, Kusrini, \& Al fatta, 2017) dan juga faktor lain dari salah memilih jurusan yaitu minimnya informasi, mengikuti pilihan orang tua, teman dengan dasar popilaritas jurusan itu sendiri, padahal salah memilih jurusan mengakibatkan kerugian waktu, finansial, dan kegagalan dalam belajar (Indrianti \& Sari, 2017).

Teknologi sistem informasi saat ini dapat dimanfaatkan untuk melihat kecocokan jurusan yang sesuai dengan minat, bakat dan kemampuan siswa
(Sucipto et al., 2017), sehingga siswa tidak lagi salah jurusan dan orang tua dapat menerima informasi yang tepat, sehingga memberikan dukungan penuh untuk memkasimalkan minat, bakat dan kemampuan anaknya. Teknologi informasi yang dapat dimanfaatkan untuk membuat rekomendasi jurusan yang tepat yaitu sistem pendukung keputusan atau decision support system (Azuansyah, 2015). Sistem pendukung keputusan merupakan system berguna untuk merekomdasikan keputusan-keputusan dari hasil pemodelan dan hasil perhitungan basis pengetahuan yang menghasilkan informasi yang interaktif sehingga dapat menghasilkan informasi keputusan yang tepat (Siregar, 2017).

Model yang banyak diusulkan dalam merancang sistem pendukung keputusan yaitu Fuzzy Multi Criteria Decision Making (FMCDM), ada beberapa metode yang digunakan dalam FMCDM yaitu Simple Additive Weighting (SAW), Weighted Product (WP), Electre, Technique for Order Prefence by Similarity to Ideal Solution (TOPSIS), dan Analytic Hierarchy Process (AHP) (Aruan, 2014). Beberapa penelitian FMCDM yang diusulkan peneliti dalam membuat sistem pendukung keputusan diantaranya adalah AHP yang diusulkan oleh (Malik \& Haryanti, 2018) pada sistem keputusan pemilihan program keahlian, metode SAW yang diusulkan (Andrianto \& Fatta, 2017) untuk membuat sistem 
pendukung keputusan dalam penerimaan beasiswa, metode ELECTRE yang diusulkan (Sahputra, Kusrini, \& Fatta, 2017) pada sistem pendukung keputusan pemilihan peguruan tinggi.

Sistem pendukung keputusan pemilihan jurusan, banyak model yang telah diusulkan oleh para peneliti, seperti metode AHP yang diusulkan oleh (Sahputra et al., 2017) dan (Sahputra et al., 2017), SAW yang diusulkan oleh (Sahputra et al., 2017) dan (Sahputra et al., 2017), KNN dan SMART (Simple Multi Attribute Rating Technique) yang diusulkan oleh (Sahputra et al., 2017), Metode Fuzzy Mamdani (Sahputra et al., 2017) dan Metode Weighted Product yang diusulkan oleh (Sianturi, 2013).

SMK PASIM Plus merupakan salah satu SMK Swasta di Kota Bumi yang menawarkan 6 (enam) Kompetensi Keahlian atau jurusan yang terdiri dari Teknik Produksi dan Penyiaran Program Pertelevisian atau TP4, Film Animasi, Akuntansi, Administrasi Perkantoran, Teknik Komputer Jaringan, dan Rekayasa Perangkat Lunak. (Web SMK PASIM PLUS, 2018, http://smkpasimplus.sch.id). Terdapat dua (2) jurusan yang paling diminati yaitu Teknik Produksi dan Penyiaran Program Pertelevisian atau TP4 dan Administrasi Perkantoran.

Penelitian ini akan mengimplementasikan model Fuzzy Multi Criteria Decision Making (FMCDM), dengan menggunakan metode Simple Additive Weighting (SAW) dalam membuat rekomendasi pemilihan jurusan pada sekolah menengah kejuruan, dengan studi kasus pada SMK PASIM Plus Kotabumi. Pemilihan metode SAW didasarkan kepada ketepatan dalam penilaian terhadap alternatif dari hasil perhitungan berdasarkan tingkat kebutuhan bobot kepetingan (Malau, 2017).

\section{METODE PENELITIAN}

Kusumadewi et al., (2006) dalam (Anwar, Sarwono, \& Djino, 2018) menyatakan bahwa Multi Criteria Decision Marking (MCDM) adalah suatu metode pengambilan keputusan untuk menetapkan alternatif terbaik dari sejumlah alternatif berdasarkan beberapa kriteria tertentu. Kriteria biasanya berupa ukuran-ukuran, aturan-aturan, atau standar yang digunakan dalam pengambilan keputusan. Kusumadewi (2006) dalam (Anwar et al., 2018) menjelaskan, terdapat beberapa fitur umum yang akan digunakan dalam MCDM yaitu:

a. Alternatif, adalah obyek-obyek yang berbeda dan memiliki kesempatan yang sama untuk dipilih oleh pengambil keputusan.

b. Atribut, atribut sering juga disebut sebagai karakteristik, komponen, atau kriteria keputusan. Meskipun pada kebanyakan kriteria bersifat satu level, namun tidak menutup kemungkinan adanya sub kriteria yang berhubungan dengan kriteria yang telah diberikan. c. Konflik antar kriteria , beberapa kriteria biasanya mempunyai konflik antar satu dengan yang lainnya, misalnya kriteria keuntungan akan mengalami konflik dengan kriteria biaya.

d. Bobot keputusan, bobot keputusan menunjukan kepentingan relatif dari setiap kriteria, $\mathrm{W}=\left(\mathrm{W}_{1}\right.$, $\left.\mathrm{W}_{2}, \ldots, \mathrm{W}_{\mathrm{n}}\right)$. Pada MCDM akan dicari bobot kepentingan dari setiap kriteria.

Matriks keputusan, suatu matriks keputusan X yang berukuran $\mathrm{m} x \mathrm{n}$, berisi elemen-elemen Xij yang mempresentasikan rating dari alternatif $\mathrm{Ai}$ $(\mathrm{i}=1,2, \ldots, \mathrm{m})$ terhadap kriteria $\mathrm{Cj}(\mathrm{j}=1,2, \ldots, \mathrm{n})$.

Metode SAW membutuhkan proses normalisasi matriks keputusan ke suatu skala yang didapat diperbandingkan dengan semua rating alternative yang ada. Formula untuk melakukan normalisasi tersebut adalah sebagai berikut:

$$
\mathrm{r}_{\mathrm{ij}}=\left\{\begin{array}{l}
\overline{\mathrm{M}}_{\mathrm{X} \overline{\mathrm{X}}_{\overline{\mathrm{X}}} \mathrm{X}_{\mathrm{ij}}} \mathrm{Jika}_{\mathrm{j}} \text { Adalah atribut benefit } \\
\frac{\mathrm{X}_{\mathrm{ij}}}{\operatorname{Max}_{\overline{\mathrm{ij}}}} \mathrm{Jika}_{\mathrm{j}} \text { Adalah Atribut cost }
\end{array}\right.
$$

Dimana dengan rij adalah rating kinerja ternormalisasi dari alternatif $\mathrm{Ai}$ pada atribut $\mathrm{Cj}: \mathrm{i}=$ $1,2 \ldots ., m$ dan $\mathrm{j}=1,2 \ldots ., \mathrm{n}$.

Keterangan:

$\operatorname{Max} \boldsymbol{X}_{i j}=$ Nilai terbesar dari setiap kriteria $\boldsymbol{i}$.

$\operatorname{Min} \boldsymbol{X}_{i j}=$ Nilai terbesar dari setiap kriteria $\boldsymbol{j}$.

$\boldsymbol{X}_{i j} \quad=$ Nilai atribut yang dimiliki dari setiap kriteria.

Benefit $=$ Jika nilai terbesar adalah terbaik.

Cost = Jika nilai terkecil adalah terbaik.

Nilai prefensi untuk setiap alternatif (Vi) diberikan rumus sebagai berikut:

$$
V_{i}=\sum_{J=1}^{n} w_{j} r_{i j}
$$

Keterangan:

$\boldsymbol{V}_{\boldsymbol{i}} \quad=$ Rangking untuk setiap alternatif.

$\boldsymbol{W}_{j} \quad=$ Nilai bobot rangking (dari setiap kriteria).

$\boldsymbol{r}_{i j} \quad=$ Nilai rating kinerja ternormalisasi.

Nilai $\boldsymbol{V}_{\boldsymbol{i}}$ yang lebih besar mengidikasikan bahwa alternatif $\boldsymbol{A}_{i}$ lebih terpilih.

\section{HASIL DAN PEMBAHASAN}

\section{Kriteria dan Alternatif}

Kriteria-kriteria yang digunakan mengacu pada aturan-aturan penentuan penjurusan bagi siswa siswa, yaitu penguasaan mata pelajaran yang di ujikan pada tahap seleksi test pengetahuan bagi calon siswa baru, tabel 1 menunjukan kriteria-kriteria yang digunakan dalam menentukan jurusan.

Aternatif yang digunakan adalah jurusan Teknologi Informasi dan Komunikasi yang ada SMK PASIM Plus Kotabumi, tabel 1 menunjukan alternatif-alternatif jurusan yang ada di SMK PASIM 
Plus Kotabumi.

Pembobotan dari setiap kriteria yang digunakan untuk pengambilan keputusan yaitu dari tingkat kepentingan dari setiap mata pelajaran, nilai pembobotan sendiri diputuskan oleh pakar. Tabel 1 menunjukan pembobotan dari setiap keriteria yang digunakan.

Tabel 1. Alternatif dan Bobot dari Setiap Kriteria

\begin{tabular}{clcll}
\hline Alternatif & Keterangan & Kriteria & Keterangan & Bobot \\
\hline A1 & Rekayasa Perangkat Lunak & C1 & Matematika & $30 \%$ \\
\hline A2 & Teknik Komputer Jaringan & C2 & Bahasa Indonesia & $20 \%$ \\
\hline A3 & Broadcasting & C3 & Bahasa Inggris & $20 \%$ \\
\hline A4 & Animasi & C4 & Teknologi Informasi & $30 \%$ \\
\hline
\end{tabular}

Sumber: (Zuama \& Sobari, 2019)

Dari tabel 1 diatas dapat diketahui bahwa kriteria pertam yaitu nilai matematika calon siswa akan mempengaruhi sebesar 30\% (0,3), kriteria kedua yaitu bahasa indonesia mempengaruhi sebesar $20 \%$ $(0,2)$, kriteria ketiga bahasa inggris akan mempengaruhi sebesar $20 \%(0,2)$ dan kriteria ke empat yait penguasaan teknologi informasi dan komunikasi (TIK) akan mempengaruhi sebesar 30\% $(0,3)$ pada setiap keputusan.

Tabel 2. Nilai Hasil Test Pengetahuan Siswa

\section{Perhitungan menggunakan FMCDM metode Simple Additive Weighting}

Misalnya calon siswa baru bernama Siti kiswah mendapatkan nilai dari hasil tes pengetahuan yang ditunjukan pada tabel 2:

\begin{tabular}{lcccc}
\hline \multirow{2}{*}{$\begin{array}{c}\text { Jurusan / } \\
\text { Alternatif }\end{array}$} & $\begin{array}{c}\text { Matematika } \\
(\mathrm{C} 1)\end{array}$ & $\begin{array}{c}\text { Bahasa } \\
\text { Indonesia } \\
(\mathrm{C} 2)\end{array}$ & $\begin{array}{c}\text { Bahasa } \\
\text { Inggris } \\
(\mathrm{C} 3)\end{array}$ & $\begin{array}{c}\text { TIK } \\
(\mathrm{C} 4)\end{array}$ \\
\hline RPL (A1) & 75 & 80 & 70 & 90 \\
\hline TKJ (A2) & 80 & 60 & 75 & 75 \\
\hline Broadcasting (A3) & 90 & 70 & 85 & 75 \\
\hline Animasi (A4) & 80 & 75 & 90 & 80 \\
\hline
\end{tabular}

Sumber: (Zuama \& Sobari, 2019)

Berdasarkan contoh calon siswa pada tabel 2, langkah-langkah penyeleksian untuk menetukan jurusan yang cocok untuk Siti kiswah dengan menggunakan Fuzzy Multi Criteria Decision Making dengan menggunakan metode SAW yaitu sebagai berikut:

a. Normalisasi

Pada tahap ini menghitung normalisasi dengan menggunakan persamaan (1). Berikut hasil perhitungan normaslisasinya.

Kriteria pertama untuk alternatif pertama:

$$
\begin{aligned}
& \text { Nor }=\frac{75}{\operatorname{Max}(75,80,90,80)}=\frac{75}{90}=0,833 \text { Kriteria kedua untuk alternatif keempat } \\
& \text { Nor }=\frac{75}{\operatorname{Max}(80,60,70,75)}=\frac{75}{80}=0,938
\end{aligned}
$$

Kriteria pertama untuk alternatif kedua

$$
\text { Nor }=\frac{80}{\operatorname{Max}(75,80,90,80)}=\frac{80}{90}=0,889
$$

Kriteria pertama untuk alternatif ketiga

$$
\text { Nor }=\frac{90}{\operatorname{Max}(75,80,90,80)}=\frac{90}{90}=1
$$

Kriteria pertama untuk alternatif keempat

$$
\text { Nor }=\frac{80}{\operatorname{Max}(75,80,90,80)}=\frac{80}{90}=0,889
$$

Kriteria kedua untuk alternatif pertama

$$
\text { Nor }=\frac{80}{\operatorname{Max}(80,60,70,75)}=\frac{80}{80}=1
$$

Kriteria kedua untuk alternatif kedua

$$
\text { Nor }=\frac{60}{\operatorname{Max}(80,60,70,75)}=\frac{60}{80}=0,75
$$

Kriteria kedua untuk alternatif ketiga

$$
\text { Nor }=\frac{70}{\operatorname{Max}(80,60,70,75)}=\frac{70}{80}=0,875
$$

Kriteria ketiga untuk alternatif pertama

$$
\text { Nor }=\frac{70}{\operatorname{Max}(70,75,85,90)}=\frac{70}{90}=0,778
$$

Kriteria ketiga untuk alternatif kedua

$$
\text { Nor }=\frac{75}{\operatorname{Max}(70,75,85,90)}=\frac{75}{90}=0,833
$$


Kriteria ketiga untuk alternatif ketiga

$$
\text { Nor }=\frac{85}{\operatorname{Max}(70,75,85,90)}=\frac{85}{90}=0,944
$$

Kriteria ketiga untuk alternatif keempat

$$
\text { Nor }=\frac{90}{\operatorname{Max}(70,75,85,90)}=\frac{90}{90}=1
$$

Kriteria keempat untuk alternatif pertama

$$
\text { Nor }=\frac{90}{\operatorname{Max}(90,75,75,80)}=\frac{90}{90}=1
$$

Kriteria keempat untuk alternatif kedua

$$
\text { Nor }=\frac{75}{\operatorname{Max}(90,75,75,80)}=\frac{75}{90}=0,833
$$

Kriteria keempat untuk alternatif ketiga

$$
\text { Nor }=\frac{75}{\operatorname{Max}(90,75,75,80)}=\frac{75}{90}=0,833
$$

Kriteria keempat untuk alternatif keempat

$$
\text { Nor }=\frac{80}{\operatorname{Max}(90,75,75,80)}=\frac{80}{90}=0,889
$$

*Nor= Normalisasi

Dari hasil perhitungan diatas maka dapat dirangkum seperti pada tabel 3:

Tabel 3. Normalisasi nilai keriteria

\begin{tabular}{crrrr}
\hline Jurusan / & \multicolumn{4}{c}{ Nilai Kriteria (normalisasi) } \\
\cline { 2 - 5 } Alternatif & \multicolumn{1}{c}{ C1 } & \multicolumn{1}{c}{ C2 } & \multicolumn{1}{c}{ C3 } & \multicolumn{1}{c}{ C4 } \\
\hline A1 & 0,833 & 1 & 0,778 & 1 \\
\hline $\mathbf{A 2}$ & 0,889 & 0,75 & 0,833 & 0,833 \\
\hline $\mathbf{A 3}$ & 1 & 0,875 & 0,944 & 0,833 \\
\hline $\mathbf{A 4}$ & 0,889 & 0,938 & 1 & 0,889 \\
\hline
\end{tabular}

Sumber:(Zuama \& Sobari, 2019)

b. Memeberikan nilai bobot (W) pada setiap keriteria

Langkah selanjutnya adalah pemberian bobot kepentingan dari setiap kriteria, berdasarkan tabel 3, pembobotan dari setiap kriteria yaitu matematika dengan bobot $30 \%(0,3)$, bahasa indonesia $20 \%(0,2)$, bahasa inggris $20 \%(0,2)$ dan TIK $30 \%(0,3)$. Tabel 4 menunjukan bobot kepentingan dari setiap kriteria.

Tabel 4. Bobot Kepentingan

\begin{tabular}{lllll}
\hline \multirow{2}{*}{$\begin{array}{l}\text { Jurusan } \\
\text { Alternatif }\end{array}$} & \multicolumn{5}{l}{ Nilai Kriteria } \\
\cline { 2 - 5 } & $\mathrm{C} 1$ & $\mathrm{C} 2$ & $\mathrm{C} 3$ & $\mathrm{C} 4$ \\
\hline Bobot & 0,3 & 0,2 & 0,2 & 0,3 \\
\hline
\end{tabular}

Sumber: (Zuama \& Sobari, 2019)

\section{c. Menghitung Perangkingan}

Pada tahap ini dilakukan perangkingan dengan menggunakan persamaan (2), berikut hasil dari perangkingan nya.

$$
\begin{aligned}
\mathrm{V} 1 & =(0,3 * 0,833)+(0,2 * 1)+(0,2 * 0,778)+(0,3 * 1) \\
& =0,250+0,2+0,156+0,3 \\
& =0,906 \\
\mathrm{~V} 2 & =(0,3 * 0,889)+(0,2 * 0,75)+(0,2 * 0,833)+(0,3 * 83) \\
& =0,267+0,15+0,167+0,25 \\
& =0,833 \\
\mathrm{~V} 3 & =(0,3 * 1)+(0,2 * 875)+(0,2 * 0,944)+(0,3 * 833) \\
& =0,3+0,175+0,189+0,25 \\
& =0,914
\end{aligned}
$$

$$
\begin{aligned}
\mathrm{V} 4 & =(0,3 * 0,889)+(0,2 * 938)+(0,2 * 1)+(0,3 * 889) \\
& =0,267+0,188+0,2+0,267 \\
& =0,921
\end{aligned}
$$

d. Hasil

Dari hasil perangkingan dapat disimpulkan bahwa nilai terbesar yaitu 0,921 (V4) maka dapat disimpulkan bahwa calon siswa baru dengan nama siswa tersebut cocok dengan mengambil jurusan A4 atau Animasi.

\section{KESIMPULAN}

Berdasarkan dari hasil penelitian yang dilakukan mengenai rekomendasi pemilihan jurusan dengann metode fuzzy multicriteria decision making (FMCDM) metode Simple Additive Weighting (SAW) maka dihasilkan kesimpulan bahwa, untuk metode SAW yang diusulkan dapat membuat rekomendasi pemilihan jurusan-jurusan yang lebih tepat untuk siswa baru. Terbukti bahwa dengan menggunakan metode yang diusulkan yaitu FMCDM dapat memprediksi hasil yang diharapkan, seperti dapat merekomendasikan keputusan jurusan-jurusan yang akan dipilih, berdasarkan pengetahuan yang dikuasai.

\section{REFERENSI}

Andrianto, C. B., \& Fatta, H. Al. (2017). Analisis Sistem Pendukung Keputusan Penerima Beasiswa Di Smp Muhammadiyah 2 Kalasan. Jurnal Teknologi Informasi, XII, 46-60.

Anwar, M. A. H., Sarwono, A. G. M., \& Djino, M. K. (2018). Studi Kasus Sistem Penunjang Keputusan, membahas metode SAW dan TOPSIS (S. R. Wicaksono, ed.). Malang: Seribu Bintang.

Aruan, A. (2014). Sistem Pendukung Keputusan Pemilihan Asuransi Jiwa Menggunakan Metode Fuzzy Multi Criteria Decision Making. Pelita Informatika Budi Darma, 4, 12-15.

Azuansyah. (2015). Sistem Penunjang Keputusan untuk Menentukan Minat Jurusan Siswa di 
SMK Al-Ikhlash Menggunakan Metode Inferensi Fuzzy Mamdani Berbasis Web ( Studi Kasus : STIKI Malang ). J-Intech, 03(January), 84-88.

Indrianti, A., \& Sari, P. I. (2017). Analisis FaktorFaktor Yang Mempengaruhi Minat Siswa Memilih Jurusan Ips Se-Kecamatan Pasar Sungai Penuh. Scientific Journals of Economic Education, 1(September), 1-10.

Malau, Y. (2017). Implementasi Metode Simple Additive Weighting Untuk Sistem Pendukung Keputusan Penentuan. Paradigma, 19(1), 3845.

Malik, A. Y., \& Haryanti, T. (2018). Penerapan Metode Analytical Hierarchy Process ( Ahp ) Untuk Sistem Pendukung Keputusan Pemilihan Program. PILAR Nusa Mandiri, 14(1), 123130.

Sahputra, E., Kusrini, \& Fatta, H. Al. (2017). Sistem Pendukung Keputusan Pemilihan Program Studi Di Perguruan Tinggi. Jurnal Ilmiah, XVIII, 1-6.

Sianturi, I. S. (2013). Sistem Pendukung Keputusan Untuk Menentukan Pemilihan Jurusan Siswa Dengan Menggunakan Metode Weighted Product (Studi Kasus: Sma Swasta Hkbp Doloksanggul). Informasi Dan Teknologi
Ilmiah, 1(1), 1-4.

Siregar, V. M. M. (2017). Perancangan Sistem Pendukung Keputusan Penentuan Jurusan Siswa/i SMA Swasta Binaguna Tanah Jawa Dengan Metode Naive Bayes. Prosiding SenNasMUDI 2017 ISBN 978-602-50396-1-4, (x), 66-75.

Sucipto, H., Kusrini, \& Al fatta, H. (2017). Sistem pendukung keputusan penerimaan siswa baru dan penjurusan pada sekolah menengah kejuruan (smk). 5(2).

Yeni Kustiyahningsih, \& Syafa'ah, N. (2014). Sistem Pendukung Keputusan Untuk Menentukan Jurusan Pada Siswa Sma Menggunakan Metode Knn Dan Smart. Jsii, 1(1), 19-28. Retrieved from http://publications.aisindo.org/index.php/JSII/a rticle/view/7/4

Zuama, R. A., \& Sobari, I. A. (2019). Implementasi Simple Additive Weighting untuk Rekomendasi Pemilihan Jurusan pada Sekolah Menengah Kejuruan. Jakarta. 